Review

\title{
Neuroscience and its Contribution to Neuroeducation for Individuals with Autism Spectrum Disorder
}

Jessica Scher Lisa, Eric Shyman *

Department of Child Study, St. Joseph's College, Patchogue, NY 11772, USA; E-Mails: jscherlisa@sjcny.edu; eshyman@sjcny.edu

* Correspondence: Eric Shyman; E-Mail: eshyman@sjcny.edu

Academic Editor: Rodolfo G. Gatto

Special Issue: Neuroimaging: Neurodegenerative Diseases and Neural Injury

OBM Neurobiology

2020, volume 4, issue 1

doi:10.21926/obm.neurobiol.2001051
Received: October 24, 2019

Accepted: February 24, 2020

Published: March 02, 2020

\begin{abstract}
With an increasing prevalence of children with Autism Spectrum Disorder (ASD) in schools, teachers are in need of different effective ways to educate these individuals who have distinctly different needs and modalities of experience. One area that has been explored is neuroeducation, or using findings from ne uroscientific research to inform classroom practice. Neuroscientific findings appear to center on two main themes of neurological differences among children with ASD: sensory processing and emotional processing. This article will review findings in these two main areas and attempt to bridge the connection between such findings and neuroeducation for children with ASD.
\end{abstract}

\section{Keywords}

Autism spectrum disorder; sensory processing; emotional processing 


\section{Introduction}

The diagnosis of Autism Spectrum Disorder (ASD) has rapidly increased in the past several decades. Data from the Center for Disease Control (CDC) has reported a 119.4 percent increase in the prevalence of ASD between 2000 and 2010. More recently, the CDC reported a 15 percent increase in the prevalence of ASD in the United States from 2016 to 2018, with new data to suggest that ASD occurs in one in 59 children [1], rendering ASD the fastest-growing developmental disability in the nation. While the exact nature of the proposed increase in ASD is highly debated, there is little question that students who are diagnosed with ASD are becoming more common in contemporary schools and classrooms [2].

Though some studies suggest that the increase in ASD is caused in part by non-etiologic factors, such as changes in diagnosis reporting practices [2-4], such studies have not been able to quantify this finding. Thus, it is evident that a considerable part of the increase in ASD prevalence is not simply explained by changes in reporting practices. This finding suggests that there is a great need to continue to examine possible etiologic factors that can account for this increase.

\section{Neurological Differences in Brains of Children with ASD}

One such avenue to explore with regard to the increase in the prevalence of ASD is the emerging research that convincingly demonstrates distinct neurological differences in both the structure and function in the brains of children diagnosed with ASD. Reviews of neuro-imaging studies in ASD through the use of structural and volumetric magnetic resonance imaging (MRI) data show highly reliable patterns. The most consistent finding to date has been accelerated brain volume growth in early childhood (an approximate $10 \%$ increase, with a peak between two and four years of age) [5]. The enlargement has been shown to occur in both grey and white matter, with some studies suggesting that in early childhood there is a disproportionate contribution by white matter to the volume increase, as well as a possible later decrease in grey matter $[6,7]$.

Research has also examined the specificity of brain region to the aforementioned enlargement, with consistent findings of abnormalities in the volume of the cerebellum and amygdalae, specifically in young children with ASD [8-12]. Volumetric abnormalities have also been documented in the frontal, temporal, and parietal lobes, thalamus, and brainstem [13-19]. Other volumetric studies have shown decreased volume in the corpus callosum, which suggests decreased inter-hemispheric connectivity in ASD, as well as increased volume of the caudate, which has been linked to the severity of repetitive behaviors [9, 20-22]. Research specific to cortical grey-matter has yielded various and inconsistent results, likely due to differences in the techniques used, as well as possible sample heterogeneity. Trends in this area have suggested increased cortical thickness in ASD, typically in younger children [5].

Another way of examining neural differences in ASD has been through the use of functional neuro-imaging (such as fMRI), specifically looking for various neurologic activity-based contributions to behavioral aspects of social cognition, language, and executive functions. Overall, fMRI studies have established clear evidence that ASD is a neurological disorder [23]. fMRI studies in this particular area have provided evidence for decreased cortical-cortical connectivity, increased connectivity between the subcortical regions and cortex, and within primary sensory 
areas such as the visual cortex [5]. These studies, in conjunction with the earlier cited finding of abnormal grey and white matter, reinforce the model of atypical connectivity in ASD [23].

These findings from fMRI studies that highlight the role of neurological differences in ASD, specifically affecting core diagnostic components (such as social cognition, language, and executive functions) have valuable and definitive educational implications. Understanding such neurological differences, and the magnitude of variability, may also help us to understand the severity level of ASD. From a diagnostic perspective, and in accordance with the Diagnostic and Statistical Manual of Mental Disorders, Fifth Edition (DSM-5), ASD is a neurodevelopmental disorder that is characterized by persistent deficits in social communication and social interaction (i.e. deficits in social-emotional reciprocity, nonverbal communicative behaviors, and establishing/maintaining social relationships), as well as by the presence of repetitive behaviors and perseverative areas of interest (i.e. stereotyped or receptive motor movements, use of objects, or speech, rigidity, restricted interests, and hyper or hyperactivity to sensory input or unusual interest in sensory aspects of the environment). Additionally, diagnoses of ASD require the presentation of symptoms in the early developmental period, marked impairments in adaptive functioning, and a lack of explanation by general intellectual impairment or global developmental delay (without these conditions may be co-occurring [24]. Furthermore, the DSM-5 outlines parameters for determining (and classifying) level of severity. Severity level is determined on the basis of functioning in two categories: social communication and restricted and repetitive behaviors. Levels range from level 1, which corresponds to a qualitative description of "requires support," through level 3, which correlates to "requires very substantial support." Examples of each level of functioning are provided in the DSM-5, and include references to verbal capabilities, as well as performance of activities of daily living, and the presence and magnitude of repetitive behaviors and perseverative interests.

\section{Neuroeducation}

Neurological differences and its impact on the variety of symptoms and resulting expression (as well as the magnitude to which they are expressed) in ASD have far-reaching implications for education. Carew and Magsamen [25] established the term neuroeducation, as a way to describe the reciprocal partnership between neuroscience and education. Neuroeducation refers to a "nascent discipline that seeks to blend the collective fields of neuroscience, psychology, cognitive science, and education to create more effective teaching methods, curricula, and educational policy. Though still in its infancy as a research discipline, this initiative is already opening critical new dialogs between teachers, administrators, parents, and brain scientists" [25]. The focus of neuroeducation is to provide "translational research" that is able to apply basic scientific discoveries in neuroscience to classroom practices, allowing teachers to make decisions based not only on theoretical educational frameworks, but also cutting edge neurological information that can apply directly to different types of learners.

In addition, Feiler and Stabio [26] identified three emerging areas of research in the field of neuroeducation that are important to consider when understanding the implications. One is the application or neuroscience to classroom learning. This refers to the application of discoveries about the brain to the classroom, or the use of neuroscience to inform innovations in education and different approaches to teaching in general. This may include instruction in reading, language, 
numeracy, attention and memory, as well as the elect of emotion, stress, and sleep on neuroplasticipty [26]. For example, Rivera et al. [27] found that younger students use different brain regions to learn arithmetic compared to older students. Specifically, younger students require assertional working memory and attention areas of the brain in order to achieve the same level of arithmetic success as older students. These findings can be applied to the classroom by way of teachers providing skills training for younger students to help them improve working memory and attention, either during or prior to, lessons on arithmetic [27].

The second major area established by Feiler and Stabio [26] is a transdisciplinary collaboration, defined in a way that suggests that the whole is greater than the sum of parts, and including terms such as integrate, transdisciplinary synergy, join, collaborate, blend, bring together, work together, synergy, combine, merge, and overlap. A strong example of this successful transdisciplinary collaboration is noted in review of a study conducted by Neville et al.[28] in which principles of neuroplasticity were used to design a family-based training program for at-risk preschool students, helping them to develop skills attention both in the classroom and at home.

The third major area established by Feiler and Stabio [26] is a translator of languages, which notes that the fields of neuroscience and education are distinct, but that educational neuroscience can help translate the languages used between the fields. In other words, this theme focuses on taking the technical jargon and complex methods of neuroscience and make them accessible to educators who may not have the requisite background knowledge to interpret the research. Examples of policy changes that have been attributed to educational neuroscience findings, that have most certainly relied in part on this translational process, inlaced adjusted school start times [29].

Inclusive of these three areas of research, Neuroeducation seeks to close an existing gap between education and neuroscience; in other words a gap between the theory and the research $[30,31]$. Even though neuroeducation is a distinctly new field, this gap has existed for decades, and was first mentioned by Dewey (1899 cited by Glennon et al. [30]). Some of the factors that are important to consider in terms of the implications of theory and educational practice are that: neuroscientific research gives us the requisite background knowledge to understand how and why learning occurs; that it can delineate differences in learning; that it can guide our design and implementation of curriculum and teaching practices; that it opens new areas of educational research; and that it could support standardization of learning practices [31-34].

In order to accomplish these tasks or goals, it is also imperative to establish a set of guidelines and parameters for critical thinkers that can distinguish between "gimmick-based" theories and practices, and those that are sound and based on legitimate neuroscientific research (e.g. "brain gym" and other "neuromyths" such as critical periods of learning and left and right brain learning, to name a few, [35]). With the increasing popularity of neuroscientific ideas about learning, there comes a challenge for teachers who want to understand how children learn, and the need to be able to distinguish between legitimate neuroscience and more commercialized and possibly inaccurate interpretations and applications of neuroscience [36]. Hardiman et al. [36] noted the importance of the availability of guidance and support for teachers to be able to utilize relevant research from the neuro and cognitive sciences, noting that without such support, teachers and schools may potentially make the mistake of utilizing non-empirically validated methods of attempting to enhance neurologic performance and nurturing neurological differences without a thorough understanding of the implications of the research. This concept stems from an emerging 
field of neuroethics, which refers to "the ethics of conducting neuro-scientific studies, (but) also the evaluation of the ethical and social impact that the results of those studies might have, or ought to have, on existing social, ethical, and legal structures," [37].

In order to translate research into practice, the use of "translators" (idea three, [26]) is likely to only bring educators so far. Understanding the neural and cognitive underpinnings of various aspects of intellectual and emotional functioning could not have been discovered without the use of neuroimaging techniques, however teachers need to be able to readily utilize such information in meaningful and relevant ways. Hardiman et al. [36] suggests that the main reason this information is not always accessible is due to the requisite amount of background knowledge necessary for teachers to have in order to move from the knowledge to the practice. In a study by [38], it was found that more than half of primary and secondary teachers believed presented neuro-myths, further supporting this notion that teachers may not be in a position to critically analyze neuroscientific findings.

Thus, it is noted that one of the primary ways of bridging this gap is to promote increased dialogue between the fields of education and neuroscience. Of particular interest may lie in utilizing a transdisciplinary approach (theme two, [26]), one which relies on collaboration between partners of differing backgrounds converging upon a shared issue, with the goal of reaching a holistic understanding [32].

Not surprisingly, one of the strongest calls for this mixed-methods type of research comes from the field of ASD in efforts to bridge the gap between neuroscientific autism research and applied social and educational autism research [39]. Studies in this area have noted that new educational interventions for learners with ASD are rarely guided by neuroscientific research, and that few studies examine how individuals with ASD are best educated in educational settings $[40,41]$.

\section{Findings of Research on Emotional Processing: Implications for Neuroeducation}

One key area that translates to neuroeducation in ASD is the group of findings that have indicated differences between the brains of individuals with ASD in emotional processing. Research has consistently demonstrated that individuals with ASD process and express emotions differently; specifically either exhibiting hypoarousal (under-excitement) or hyperarousal (overexcitement) of emotion regulation centers, and a core difference in the processing of socioemotional information. A number of studies have looked at facial processing as an approximation of emotional processing.

Dawson et al. [42] used Event Related Potentials (ERPs) to compare ne ural activation between 29 three and four year olds with ASD as compared to 22 control children, matched by age. Theoretical basis for this research centered around the theory that individuals with ASD exhibit impairments in facial recognition, and that neuroimaging studies have consistently demonstrated that individuals with ASDs exhibit abnormal patterns of brain activity during facial processing. The study examined the temporal characteristics of face processing in ASD and its relation to behavior using ERPs in response to images of faces, inverted faces, and objects. Results indicated that the children with ASD showed little difference in neural activation when viewing a fearful face and neutral face, while the children without ASD showed neural modulation when processing the different facial expressions. From a neuroeducational perspective, the results of this study demonstrated evidence for slowed neural speed of face processing in ASD, and highlight the role 
of (slow) speed of processing faces in impairments in ASD. The translation of this research into neuroeducation is multifaceted in that is both suggestive of the need to provide students with ASD with specific training on reading facial expressions and related emotions, as well as providing students with ASD with extended time for processing facial cues.

In a related study, Corbett, et al. [43] compared fMRIs demonstrating reaction to facial processing between 12 eight to 12 year old children with ASD compared to 15 age-matched students without ASD. Of particular interest was the amygdala (a core structure that is centrally located in socioemotional functioning). Structural and functional MRI data were collected. Results suggested reduced activation in the fusiform gyrus area, which has been shown by a number of studies to be central in facial processing, as compared to the non-ASD participants. Associations were also demonstrated between age, social anxiety, and amygdala volume in children with ASD (smaller volumes were associated with increased anxiety and younger age). In terms of neuroeducational implications, it can be inferred that the amygdala in persons with ASD provide the socioemotional relevance and context to other (atypical) brain regions, such as the fusiform gyrus, during social situations [43]. It was also speculated in this research that the limited engagement of the amygdala results in a dysfunctional connection between the amygdala and fusiform gyrus in children with ASD, resulting in a lack of social preference and/or poor eyecontact. To translate this research into a neuroeducational perspective, it would be important for educators to understand the link between impaired emotion recognition to eliciting appropriate social responses. Thus, in order to assist and educate students with ASD in reading and responding to social cues beyond rote memorization and scripted responses, it will be imperative to build in the underpinnings of emotion recognition in facial processing in order to facilitate the desired social gains (including not only appropriate social responses, but also improvements in eye contact, and quite likely the desire for social interactions).

Philip, Whalley, Stanfield et al. [44] examined emotional facial, body, and goal processing in 23 adults with 23 age-matched non-ASD controls. Recognition of basic emotions was assessed by facial, body movement, and vocal stimuli. The ability to make social judgements from facial stimuli was investigated. Emotion processing ability was assessed using a variety of face, body movement, and voice tasks, as well as tests of social judgement. Results indicated that significant differences are, in fact, present in emotion recognition in persons with ASD across all stimulus domains and emotions. The ASD group was also impaired in making social judgement (likely as a realist of impairment in basic emotion recognition). From a neuro-education perspective, knowing this information helps bring understanding to the impairments in social functioning seen in ASDs, namely as a result of the core deficits that affect the processing of a range of emotions. Neuroeducational implications of this research are similar to what was noted previously with regard to the research of Corbett et al. [43].

Other studies have examined the role of the amygdala in emotional processing differences for individuals with ASD. Schumann, Barnes, and Lord et al. [10] compared the amygdala volume in 89 toddlers, 41 of whom were later diagnosed with ASD. Amygdala volumes were determined based on MRI scans. The size of the right and left amygdalae were significantly larger $(p<.05)$ as compared to toddlers who were not diagnosed with ASD. Of further interest, the size of the amygdala was positively correlated with ASD severity as determined on the Autism Diagnostic Interview - Revised (ADI-R) and Vineland Scales of Adaptive Behavior. Interestingly, this contributes to an existing body of research that evidences that the amygdala is enlarged in young 
children with autism [45-47], contrasted with findings of older persons with autism that typically find that amygdala volume is smaller in ASD relative to age-matched controls [48-50]. From a practical perspective, it can be surmised that smaller amygdala volume in older children and adolescents with ASD is related to gaze avoidance and more severe behavioral impairments [49]. It has also been implicated that abnormalities in the amygdala in ASDs, as well as the related deficit of early attention to faces, may be the first of a cascade of difficulties that lead to later emotional and social impairments [51-53]. Neuroeducational implications of this research are multifaceted, from highlighting the known importance of early intervention, but more importantly drawing attention to the potential mitigation of a lack of attention to or awareness of faces. This is not necessarily a common goal or target of behavioral programs for young children with ASD, which is suggestive of the known lack of neuroeducation in general. Translating this research into practice could potentially mediate the cascade of difficulties that lead to some of the greater emotional, behavioral, and social impairments in ASD.

Taking a different approach, Schumann and Amaral [54] conducted a study involving the number of neurons present in the amygdala of individuals with ASD. Nine male ASD and 10 agematched non-ASD postmortem brains were examined in the study. While no difference in volume was found, there was a significant difference in neural presence, with the individuals with ASD showing less overall neurons in the amygdala as compared to the individuals without ASD. It was concluded that the amygdala in ASD undergoes an abnormal pattern of postnatal development that includes early enlargement and an ultimately reduced number of neurons.

In a related study by Kleinhans, Johnson, Richards et al. [55], fMRI was used to study the process of neuronal habituation in 24 individuals with ASD and 23 age-matched controls without ASD, between the ages of 16 and 25 years. The results showed that individuals with ASD possessed significantly less neurons than those without ASD, with less neuronal habituation correlating with higher severity of ASD. It was further concluded that amygdala hyperarousal was present in ASDs in response to socially relevant stimuli, and that sustained amygdala arousal may contribute to the social deficits observed in ASDs. Previous research supports the theory that habituation in the amygdala affects social orienting responses [56]. Difficulties with social orienting are well established in ASDs, and one possible explanation is that the amygdala dysfunction results in difficulty discriminating between salient and non-salient social information. This stimulus overload, which is a function of the failure of neurons in the amygdala to habituate to less-important stimuli, may have serious implications in terms of social dysfunction [55]. Interestingly, results of the aforementioned study also found that participants with the most severe social impairments exhibited the least amount of amygdala habituation to faces. From a neuroeducational perspective, the fact that the individuals who showed the least amount of neural habituation had the greatest social impairments suggests that difficulties in social cognition in ASDs may be associated with the abnormalities in this basic function of learning [55]. As such, efforts focused on training social cognition may have the greatest benefits in terms on improving social and emotional functioning.

The aforementioned research is a prime example of how advances in neuroimaging can have a distinct impact on the direction and quality of education provided for individuals with ASD [57]. The research on emotional processing in ASD highlights both deficits in ASD that need to be addressed in the educational setting as well as suggestions for pathways to achieving positive outcomes in education surrounding emotional competence. For example, in a study by Ravet and 
Williams [35], an educational drama program was designed in effort to teach secondary students with ASD imitation and empathy skills relating to emotions, and whether that could promote social skills in children with ASD. The researchers designed the program utilizing a combination of neuroscientific research and educational theory via a transdisciplinary approach (two clinical researchers, an educational researcher, and a drama specialist). In this model, the educational researcher did not need to evaluate and translate neuroscientific theory, as that role was fulfilled by the clinical researchers on the transdisciplinary team, thereby avoiding neuromyths and other related pitfalls. Similarly, the neuroscientist within the group was able to gain some understanding of the educational issues during the empirical phase of the study. Results of the pilot study were suggestive of success in the ability of children with ASD to learn emotional imitation.

\section{Further Implications for Neuroeducation}

Since neuroscientific information is not always readily available to or utilized by teachers, it is imperative that the field of neuroeducation make it possible for teachers to appropriately apply these neuroscientific findings to their classroom practices. Speculating on the efficacy of this process, Hardiman et al. [36] pointed out five relevant ideas that pertain to the ethical dissemination of neuroeducation to the teaching profession: (a) what teachers can expect from science and what their responsibilities are when interpreting the research, (b) what researchers should contribute in terms of the role of "translator" in efforts to inform teaching and learning, (c) how the media and publication companies should portray scientific findings, (d) how educational policy makers should realign the priorities to focus on the science behind learning, and (e) the role of universities (specifically educational training programs) in facilitating this change.

It is without a doubt that universities, and specifically teacher preparation programs, need to be more proficient in cultivating teachers who are adept consumers of research, and able to translate science into practice. Such programs need to be at the forefront of this movement to advance the field of neuroeducation. Research by Ravet and Williams [35] is suggestive of the transdisciplinary approach, which could be achieved through the hiring and training of multidisciplinary specialists to help bridge the gap between science and the practice of teaching, as well as expanding their reach by providing ongoing professional development for the educational community at-large.

Another possible avenue for achieving aforementioned goals is through the role of "neuroeducators" proposed by Schwartz [58]. These neuroeducators are researchers who are trained to understand the intricacies of the gap between neuroscientific theory and educational practice, and work to facilitate interactions between researchers and educators. This approach is certainly not without an array of complexities, including funding, resourcing, and resistance.

In conclusion, it is clear that neuroscientific research is able to guide the field of education on both the types of strategies that learners need (e.g. children with ASD and the potential benefit of targeted instruction in emotion recognition and empathy training), as well as the services that learners may benefit from (e.g. increased time for children with ASD to process emotional information).

Lastly, it is imperative that research within the transdisciplinary method of neuroeducation continues in order to further the field of neuroeducation and its benefits on the learning potentials of not only students with ASD, but all learners across educational settings. 


\section{Author Contributions}

Jessica Scher Lisa, Psy.D. constructed the main narrative, including organization, and provided the main revisions for this review paper. Eric Shyman, Ed.D. completed much of the literature review and summarization of the studies related in this review paper. The concept for the paper was determined jointly.

\section{Competing Interests}

The authors have declared that no competing interests exist.

\section{References}

1. Baio J, Wiggins L, Christensen DL, Maenner MJ, Daniels J, Warren Z, et al. Prevalence of autism spectrum disorder among children aged 8 years - Autism and Developmental Disabilities Monitoring Network, 11 Sites, United States, 2014. MMWR Surveill Summ. 2018; 67: 1-23.

2. Hansen SN, Schendel DE, Parner ET. Explaining the increase in the prevalence of autism spectrum disorders: The proportion attributable to changes in reporting practices. JAMA Pediatrics. 2015; 169: 56-62.

3. Nassar N, Dixon G, Bourke J, Bower C, Glasson E, De Klerk N, et al. Autism spectrum disorders in young children: Effect of changes in diagnostic practices. Int J Epidemiol. 2009; 38: 12451254.

4. Lauritsen $M$, Pedersen $C$, Mortensen $P$. The incidence and prevalence of pervasive developmental disorders: A Danish population-based study. Psychol Med. 2004; 34: 13391346.

5. Anagnostou E, Taylor MJ. Review of neuroimaging in autism spectrum disorders: What have we learned and where we go from here. Mol Autism. 2011; 2: 4.

6. Herbert M, Ziegler D, Deutsch C, O'brien L, Lange N, Bakardjiev A, et al. Dissociations of cerebral cortex, subcortical and cerebral white matter volumes in autistic boys. Brain. 2003; 126: 1182-1192.

7. Courchesne E, Karns C, Davis H, Ziccardi R, Carper R, Tigue Z, et al. Unusual brain growth patterns in early life in patients with autistic disorder: An MRI study. Neurology. 2001; 57: 245-254.

8. Courchesne E, Yeung-Courchesne R, Hesselink J, Jernigan T. Hypoplasia of cerebellar vermal lobules VI and VII in autism. N EngI J Med. 1988; 318: 1349-1354.

9. Stanfield AC, Mclntosh AM, Spencer MD, Philip R, Gaur S, Lawrie SM. Towards a neuroanatomy of autism: A systematic review and meta-analysis of structural magnetic resonance imaging studies. Eur Psychiatry. 2008; 23: 289-299.

10. Schumann CM, Barnes CC, Lord C, Courchesne E. Amygdala enlargement in toddlers with autism related to severity of social and communication impairments. Biol Psychiatry. 2009; 66: 942-949.

11. Zeegers $M$, Hulshoff Pol $H$, Durston $S$, Nederveen $H$, Schnack $H$, van Daalen $E$, et al. No differences in MR-based volumetry between 2- and 7-year-old children with a utism spectrum disorder and developmental delay. Brain Dev. 2009; 31: 725-730. 
12. Dziobek I, Fleck S, Rogers K, Wolf OT, Convit A. The 'amygdala theory of autism'revisited: linking structure to behavior. Neuropsychologia. 2006; 44: 1891-1899.

13. Haznedar MM, Buchsbaum MS, Hazlett EA, LiCalzi EM, Cartwright C, Hollander E. Volumetric analysis and three-dimensional glucose metabolic mapping of the striatum and thalamus in patients with autism spectrum disorders. Am J Psychiatry. 2006; 163: 1252-1263.

14. Herbert MR, Ziegler DA, Makris N, Filipek PA, Kemper TL, Normandin JJ, et al. Localization of white matter volume increase in autism and developmental language disorder. Ann Neurol. 2004; 55: 530-540.

15. Kwon H, Ow AW, Pedatella KE, Lotspeich LJ, Reiss AL. Voxel-based morphometry elucidates structural neuroanatomy of high-functioning autism and Asperger syndrome. Dev Med Child Neurol. 2004; 46: 760-764.

16. Rojas DC, Camou SL, Reite ML, Rogers SJ. Planum temporale volume in children and adolescents with autism. J Autism Dev Dis. 2005; 35: 479-486.

17. Courchesne E, Press G, Yeung-Courchesne R. Parietal lobe abnormalities detected with MR in patients with infantile autism. AJR Am J Roentgenol. 1993; 160: 387-393.

18. Tsatsanis KD, Rourke BP, Klin A, Volkmar FR, Cicchetti D, Schultz RT. Reduc ed thalamic volume in high-functioning individuals with autism. Biol Psychiatry. 2003; 53: 121-129.

19. Rodier PM. Converging evidence for brain stem injury in autism. Dev Psychopathol. 2002; 14: 537-557.

20. Hardan AY, Libove RA, Keshavan MS, Melhem NM, Minshew NJ. A preliminary longitudinal magnetic resonance imaging study of brain volume and cortical thickness in autism. Biol Psychiatry. 2009; 66: 320-326.

21. Hollander E, Anagnostou E, Chaplin W, Esposito K, Haznedar MM, Licalzi E, et al. Striatal volume on magnetic resonance imaging and repetitive behaviors in autism. Biol Psychiatry. 2005; 58: 226-232.

22. Sears LL, Vest C, Mohamed S, Bailey J, Ranson BJ, Piven J. An MRI study of the basal ganglia in autism. Prog Neuro-psychopharmacol Biol Psychiatry. 1999.

23. Minshew NJ, Keller TA. The nature of brain dysfunction in autism: Functional brain imaging studies. Curr Opin Neurol. 2010; 23: 124.

24. Association AP. Diagnostic and statistical manual of mental disorders $\left(D S M-5^{\circledR}\right)$ : American Psychiatric Pub; 2013.

25. Carew TJ, Magsamen SH. Neuroscience and education: An ideal partnership for producing evidence-based solutions to guide 21st century learning. Neuron. 2010; 67: 685-688.

26. Feiler JB, Stabio ME. Three pillars of educational neuroscience from three decades of literature. Trends Neurosci Edu. 2018; 13: 17-25.

27. Rivera SM, Reiss A, Eckert MA, Menon V. Developmental changes in mental arithmetic: Evidence for increased functional specialization in the left inferior parietal cortex. Cereb Cortex. 2005; 15: 1779-1790.

28. Neville HJ, Stevens C, Pakulak E, Bell TA, Fanning J, Klein S, et al. Family-based training program improves brain function, cognition, and behavior in lower socioeconomic status preschoolers. Proc Nat Acad Sci. 2013; 110: 12138-12143.

29. Thomas MS, Ansari D, Knowland VC. Annual research review: Educational neuroscience: Progress and prospects. J Child Psychol Psychiatry. 2019; 60: 477-492. 
30. Glennon C, Hinton C, Callahan T, Fischer KW. School-based research. Mind Brain Edu. 2013; 7: 30-34.

31. Donovan MS. Generating improvement through research and development in education systems. Science. 2013; 340: 317-319.

32. Samuels BM. Can the differences between education and neuroscience be overcome by mind, brain, and education? Mind Brain Edu. 2009; 3: 45-55.

33. Howard-Jones P. Neuroscience and education: Issues and ppportunities. A commentary by the Teaching and Learning Research Programme. 2007.

34. Blakemore S, Frith U. Report on the implications of recent developments in neuroscience for research on teaching and learning. ESRC Teaching and Learning Research Programme London: Institute of Cognitive Neuroscience. 2000.

35. Ravet J, Williams JH. What we know now: Education, neuroscience and transdisciplinary autism research. Edu Res. 2017; 59: 1-16.

36. Hardiman M, Rinne L, Gregory E, Yarmolinskaya J. Neuroethics, neuroeducation, and classroom teaching: Where the brain sciences meet pedagogy. Neuroethics. 2012; 5: 135-143.

37. Roskies A. Neuroethics for the new millenium. Neuron. 2002; 35: 21-23.

38. Dekker S, Lee NC, Howard-Jones P, Jolles J. Neuromyths in education: Prevalence and predictors of misconceptions among teachers. Front Psychol. 2012; 3: 429.

39. Dunlop A-W, McGregor E, Marwick H, Ravet J, Robinson A, Rydzewska E, et al. Action on autism research in Scotland: An advanced international multidisciplinary, multi-agency research seminar series held between November 2013 and November 2014. Univesity of Strathprints Glasgow. 2016.

40. Pellicano L, Dinsmore A, Charman T. A future made together: Shaping autism research in the UK. 2013.

41. Pellicano E, Dinsmore A, Charman T. What should autism research focus upon? Community views and priorities from the United Kingdom. Autism. 2014; 18: 756-770.

42. Dawson G, Webb SJ, McPartland J. Understanding the nature of face processing impairment in autism: Insights from behavioral and electrophysiological studies. Dev Neuropsychol. 2005; 27: 403-424.

43. Corbett BA, Carmean V, Ravizza S, Wendelken C, Henry ML, Carter C, et al. A functional and structural study of emotion and face processing in children with autism. Psychiatry Res. 2009; 173: 196-205.

44. Philip R, Whalley H, Stanfield A, Sprengelmeyer R, Santos I, Young A, et al. Deficits in facial, body movement and vocal emotional processing in autism spectrum disorders. Psychol Med. 2010; 40: 1919-1929.

45. Schumann CM, Hamstra J, Goodlin-Jones BL, Lotspeich LJ, Kwon H, Buonocore MH, et al. The amygdala is enlarged in children but not adolescents with autism; The hippocampus is enlarged at all ages. J Neurosci. 2004; 24: 6392-6401.

46. Sparks B, Friedman S, Shaw D, Aylward EH, Echelard D, Artru A, et al. Brain structural abnormalities in young children with autism spectrum disorder. Neurology. 2002; 59: 184-192.

47. Mosconi MW, Cody-Hazlett H, Poe MD, Gerig G, Gimpel-Smith R, Piven J. Longitudinal study of amygdala volume and joint attention in 2-to 4-year-old children with autism. Arch Gen Psychiatry. 2009; 66: 509-516. 
48. Aylward EH, Minshew N, Goldstein G, Honeycutt N, Augustine A, Yates K, et al. MRI volumes of amygdala and hippocampus in non-mentally retarded autistic adolescents and adults. Neurology. 1999; 53: 2145.

49. Nacewicz BM, Dalton KM, Johnstone T, Long MT, McAuliff EM, Oakes TR, et al. Amygdala volume and nonverbal social impairment in adolescent and adult males with autism. Arch Gen Psychiatry. 2006; 63: 1417-1428.

50. Pierce K, Müller R-A, Ambrose J, Allen G, Courchesne E. Face processing occurs outside the fusiformface area'in autism: Evidence from functional MRI. Brain. 2001; 124: 2059-2073.

51. Pierce $K$, Haist F, Sedaghat F, Courchesne $E$. The brain response to personally familiar faces in autism: Findings of fusiform activity and beyond. Brain. 2004; 127: 2703-2716.

52. Schultz RT. Developmental deficits in social perception in autism: The role of the amygdala and fusiform face area. Int J Dev Neurosci. 2005; 23: 125-141.

53. Osterling J, Dawson G. Early recognition of children with autism: A study of first birthday home videotapes. J Autism Dev Dis. 1994; 24: 247-257.

54. Schumann CM, Amaral DG. Stereological analysis of amygdala neuron number in autism. J Neurosci. 2006; 26: 7674-7679.

55. Kleinhans NM, Johnson LC, Richards T, Mahurin R, Greenson J, Dawson G, et al. Reduced neural habituation in the amygdala and social impairments in autism spectrum disorders. Am J Psychiatry. 2009; 166: 467-475.

56. Fischer $\mathrm{H}$, Wright $\mathrm{Cl}$, Whalen PJ, Mclnerney SC, Shin LM, Rauch SL. Brain habituation during repeated exposure to fearful and neutral faces: A functional MRI study. Brain Res Bull. 2003; 59: 387-392.

57. Shyman E. Please wait, processing: A selective literature review of the neurological understanding of emotional processing in ASD and its potential contribution to neuroeducation. Brain Sci. 2017; 7: 153.

58. Schwartz M. Mind, brain and education: A decade of evolution. Mind Brain Edu. 2015; 9: 6471.

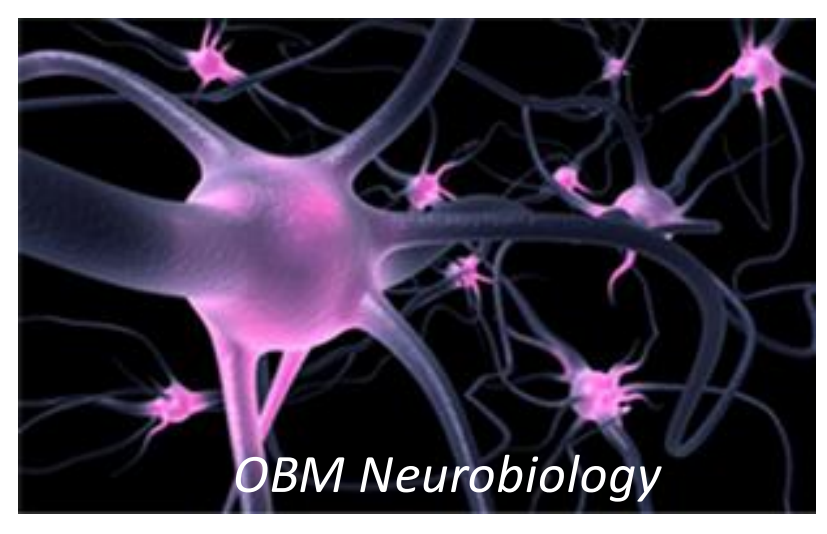

Enjoy OBM Neurobiology by:

1. Submitting a manuscript

2. Joining volunteer reviewer bank

3. Joining Editorial Board

4. Guest editing a special issue

For more details, please visit: 